\title{
Oxygenation Does Not Stimulate Hepatic Gluconeogenesis in Fetal Lambs
}

\author{
CHRISTINE A. GLEASON AND ABRAHAM M. RUDOLPH \\ Cardiovascular Research Institute and the Departments of Pediatrics, Physiology, and Obstetrics, Gynecology, \\ and Reproductive Sciences, University of California, San Francisco, and Mount Zion Hospital,
} San Francisco, California

\begin{abstract}
We have previously shown that the healthy fetal lamb liver does not release glucose and does not demonstrate gluconeogenesis. Shortly after birth, however, the liver releases glucose both by glycogenolysis and by gluconeogenesis. Previously it has been suggested that increased oxygen availability stimulates hepatic gluconeogenesis at birth. To test this hypothesis, we increased fetal arterial blood $\mathrm{pO}_{2}$ by ventilating the fetus with high oxygen gas mixtures in utero. We placed intravascular catheters in the right or left hepatic vein, umbilical vein, inferior vena cava, and descending aorta and inserted a large polyvinyl tube into the trachea of seven fetal lambs at $134 \pm$ 2.2 days gestation. Studies were done several days after surgery. ${ }^{14} \mathrm{C}$-lactate was infused intravenously and ${ }^{14} \mathrm{C}$ glucose concentrations were measured in hepatic venous and umbilical venous blood during a control period, during ventilation with $5 \% \mathrm{CO}_{2}, 3 \% \mathrm{O}_{2}, 92 \% \mathrm{~N}_{2}$, and then during ventilation with $5 \% \quad \mathrm{CO}_{2}$ and $95 \% \mathrm{O}_{2}$. The difference between these two measurements represented hepatic gluconeogenesis. Arterial blood glucose concentrations and blood gases were also measured during each study period. Ventilation with $3 \% \mathrm{O}_{2}$ did not significantly change arterial $\mathrm{PO}_{2}$ but ventilation with $95 \%$ oxygen increased mean arterial $\mathrm{pO}_{2}$ from a control of 16.7 to 156.3 torr. Mean arterial blood glucose concentration increased significantly from a control of 11.9 to $17.6 \mathrm{mg} / \mathrm{dl}$ during ventilation with $3 \% \mathrm{O}_{2}$ and to $19.1 \mathrm{mg} / \mathrm{dl}$ during ventilation with $95 \% \mathrm{O}_{2}$. However, the hepatic-umbilical venous ${ }^{14} \mathrm{C}$-glucose concentration difference was not significant when control values were compared with each ventilation period. We conclude that an acute increase in fetal oxygenation does not stimulate hepatic gluconeogenesis in near-term fetal lambs. (Pediatr Res 20: 532-535, 1986)
\end{abstract}

Abbreviations

HV, hepatic vein

UV, umbilical vein

The liver of the fetal lamb is metabolically very active as evidenced by the large blood flow and oxygen consumption. However, as shown by Bristow et al. (1) there is no net uptake or release of glucose by the fetal liver, and recently we have also shown that there is no gluconeogenesis in the liver of the fetal lamb (2). The lack of glucose production by the liver is not

Received November 6, 1985; accepted February 3, 1986.

Address correspondence to A. M. Rudolph, M.D., University of California, 1403 HSE, San Francisco, CA 94143.

This work was supported by Program Project Grant HL-24056 from the U.S. Public Health Service. surprising, because glucose is delivered to the fetus from the mother through the placental circulation and fetal gluconeogenesis would be metabolically extravagant. However, the lamb must activate hepatic gluconeogenesis within $24 \mathrm{~h}$ of birth because the maternal glucose supply is no longer available and glycogen stores are rapidly depleted. Stevenson et al. (3) have shown that the key gluconeogenic enzymes are present in fetal sheep at greater than adult levels at term. Warnes et al. (4) found that gluconeogenesis was active within 2 min after delivery of lambs by cesarian section but the actual mechanism that stimulates activity of the gluconeogenic pathway at birth is not known. There has been considerable speculation regarding control of this pathway by glucagon $(5-8)$, thyroid hormone $(9,10)$, fatty acid oxidation (11), postnatal hypoglycemia (12), and oxygen availability (4). The increase in oxygen availability is believed to be a likely mechanism but studies have not been done to test the theory in vivo.

We have previously described a method for evaluating fetal liver metabolism in utero (13). Using this method in conjunction with placement of a tracheal tube to ventilate fetuses in utero, we sought to assess whether the increase in blood oxygen content after birth stimulates hepatic gluconeogenesis.

\section{METHODS}

Surgical preparation. Pregnant ewes with gestational age 128 135 days (term 145 days) were fasted for $24-42 \mathrm{~h}$ before surgery. Surgery was performed under epidural anesthesia with 2-4 ml $1 \%$ tetracaine hydrochloride. Ketamine $(100 \mathrm{mg})$ was administered intravenously every 15-30 min for sedation. Local anesthesia with $0.25 \%$ lidocaine hydrochloride was used for all fetal incisions. A continuous intravenous infusion of $10 \%$ dextrose in $0.9 \% \mathrm{NaCl}$ was given to the ewe throughout the surgery.

In the ewe, polyvinyl catheters $(2.3 \mathrm{~mm}$ outside diameter, 1.3 $\mathrm{mm}$ internal diameter) were inserted into the pedal vein and artery and advanced into the inferior vena cava and descending aorta using techniques we have described previously. In the fetus, polyvinyl catheters $(1.2 \mathrm{~mm}$ outside diameter, $0.75 \mathrm{~mm}$ internal diameter) were inserted into the descending aorta, the umbilical vein, the inferior vena cava, and either the right $(n=2)$ or the left $(n=5)$ hepatic vein by previously described methods (13). Briefly, a 3- to 4-cm incision was made in the uterine horn over a fetal hind limb. Catheters were inserted into a fetal pedal vein and artery and advanced to the descending aorta and the inferior vena cava. The amnion was then separated from the allantoic membrane to expose a large umbilical vein along the mesenteric border of the uterus. A small cotyledonary tributary entering this vein was isolated, and a catheter was introduced via the cotyledonary vein and advanced $12-15 \mathrm{~cm}$ into the larger umbilical vein. The position of the fetal right chest was then identified by palpating the spine and ribs, and the uterus was extracted further to expose this area. A right thoracotomy was performed through 
the eighth intercostal space and the right lung was retracted, exposing the diaphragm and inferior vena cava. The inferior vena cava was punctured through a purse-string suture just caudal to the entry of the diaphragmatic vein, and a catheter was then advanced either into the right hepatic vein (slightly ventral and to the right) or into the left hepatic vein (ventral and to the left). In addition, a tube was placed in the fetal trachea by exposing the trachea through a 2-cm incision on the side of the neck. The trachea was ligated at its cranial end. A small incision was made into the lumen, and a no. $12 \mathrm{~F}$ polyvinyl tube was inserted so that the tip was positioned just beyond the clavicle. The tube was tied in position and immediately clamped off so that no lung fluid was lost. All catheters were exteriorized to the maternal flank, and the tracheal and amniotic cavity tubes were joined with a metal connector.

After surgery, the ewes recovered for at least 3-5 days before study, and were fed a standard diet of alfalfa pellets. All vascular catheters were flushed daily and filled with heparin solution (1 $\mathrm{mg} / \mathrm{ml}$ ). Antibiotics (penicillin, 1,000,000 $\mathrm{U}$ and kanamycin, $400 \mathrm{mg}$ ) were administered intravenously to the ewe and were instilled into the amniotic cavity daily.

\section{EXPERIMENTAL PROTOCOL}

On the day of study, the ewe was placed in a metabolic study cage and allowed access to alfalfa pellets and water.

A blood sample $(0.5 \mathrm{ml})$ was drawn from the fetal descending aorta and analyzed for $\mathrm{pH}$, hemoglobin concentration, and blood gases. Then, a bolus of ${ }^{14} \mathrm{C}$-lactate $(40-50 \mu \mathrm{Ci}$, New England Nuclear, $150-170 \mathrm{mCi} / \mathrm{mmol}$ ) was injected into the fetal inferior vena cava. The bolus was followed by an infusion of ${ }^{14} \mathrm{C}$-lactate $(30-50 \mu \mathrm{Ci} / \mathrm{h}, 0.1 \mathrm{ml} / \mathrm{min})$. At 30 and $60 \mathrm{~min}$ after the ${ }^{14} \mathrm{C}$ lactate bolus had been injected, blood samples $(1.8 \mathrm{ml})$ were withdrawn from the fetal descending aorta, umbilical vein, and hepatic vein, and from the maternal artery for analysis of glucose, lactate, and ${ }^{14} \mathrm{C}$-glucose concentration and $\mathrm{pH}$, hemoglobin concentration, and blood gases.

The tracheal catheter was then disconnected from the amniotic catheter and allowed to drain lung fluid. We used a 3-way adaptor to ventilate the fetus manually with a gas mixture of $3 \% \mathrm{O}_{2}, 5 \%$ $\mathrm{CO}_{2}$, and $92 \% \mathrm{~N}_{2}$ at a rate of $40-50$ breaths/min. Inspiratory pressure was regulated by flow rate and end-expiratory pressure by manual pressure at the adaptor. Inspiratory pressures were not measured at the tracheal level. The pressure measured in the ventilated tube outside the maternal abdomen had peak inspiratory levels of $30-40 \mathrm{~mm} \mathrm{Hg}$ and end-expiratory levels of 6$10 \mathrm{~mm} \mathrm{Hg}$. Minor adjustments in the gas concentrations were made so that fetal arterial blood gases were maintained close to control valves. Ventilation was continued for $15 \mathrm{~min}$ and blood samples were then drawn as in the control period. The gas mixture was then changed to $5 \% \mathrm{CO}_{2}$ and $95 \% \mathrm{O}_{2}$ and ventilation was continued for 15-55 min (mean $32 \mathrm{~min}$ ) and blood samples were again drawn. Blood gases were measured frequently during this period and blood samples were drawn when the fetal arterial $\mathrm{pO}_{2}$ had increased significantly from control values.

All blood withdrawn from the fetus was immediately replaced with an equal volume of donor fetal blood or, if this was not available, with maternal blood.

Seven fetal sheep were studied on the 1st day and five of these fetuses were still alive $24 \mathrm{~h}$ after the study. The remaining two fetuses were delivered by cesarean section after the study was completed. One of these developed a right pneumothorax after delivery, and died within $30 \mathrm{~min}$. The other fetus breathed spontaneously and had normal newborn blood gases after $1 \mathrm{~h}$.

\section{MEASUREMENTS}

Blood glucose and lactate concentrations were measured in duplicate by enzymatic methods (Sigma Co.). Reproducibility of results is within $2 \%$ in our laboratory.
${ }^{14} \mathrm{C}$-glucose radioactivity was measured by the radiochemical method described by Hay et al. (14). Briefly, aliquots of deproteinized blood were mixed either with glucose oxidase or with deionized water, and were then passed through anion exchange columns (Aminex 1-X8, 100-200 mesh, Bio-Rad). Blood samples mixed with glucose oxidase eluted small amounts of glucose, glucose being retained on the column as gluconate $(95-99 \%$ retention). Blood samples without glucose oxidase eluted 95$99 \%$ glucose. The samples were evaporated to dryness and were then resuspended wtih deionized water. Radioactivity was measured in a $\beta$ liquid scintillation counter (Beckman). The difference between the counts $(\mathrm{dpm} / \mathrm{ml})$ from the two columns yielded the amount of radioactive glucose in the blood sample. All results were corrected for the percentage retention and for percentage recovery of a known amount of ${ }^{14} \mathrm{C}$-glucose analyzed during each assay. Because nearly $95 \%$ of the ${ }^{14} \mathrm{C}$-lactate was retained by the columns, the actual ${ }^{14} \mathrm{C}$-radioactivity obtained in each aliquot was small $(30-60 \mathrm{cpm})$ and so the $\mathrm{SD}$ of each ${ }^{14} \mathrm{C}$-glucose measurement was quite large (10-25\%).

Total ${ }^{14} \mathrm{C}$-radioactivity (substrates and glucose) in each blood sample was measured by adding $1 \mathrm{ml}$ of a $1: 1$ solution of isopropanol and Soluene-350 (Packard Instrument Co.) to 0.1 $\mathrm{ml}$ of whole blood. After denaturation $(24 \mathrm{~h}), 0.5 \mathrm{ml}$ of $3 \%$ hydrogen peroxide was added to each sample. Ten ml of Scintiverse II was then added and the dpm were counted in a $\beta$ liquid scintillation counter.

Oxygen saturation and hemoglobin concentration were measured by a Radiometer hemoximeter (OSM2). Blood gases were measured using a Corning blood gas analyzer.

\section{CALCULATIONS}

Hepatic gluconeogenesis. During ${ }^{14} \mathrm{C}$-lactate infusion, the total ${ }^{14} \mathrm{C}$-radioactivity in the blood samples remained fairly constant over the 2- to 3-h study period; the mean variability over time was $18.2 \%$. To assess any changes in hepatic gluconeogenesis during ventilation and oxygenation, we compared the difference in ${ }^{14} \mathrm{C}$-glucose and glucose concentrations measured in the $\mathrm{HV}$ UV during the control period to that measured during the ventilation periods. Because measurements of blood flow were not considered, we determined this measure of hepatic gluconeogenesis only and did not measure rates of hepatic glucose production.

Statistical analysis. Differences between measurements in the control, ventilated, and ventilated/oxygenated periods were analyzed by the paired $t$ test. Correlation between measurements was done by linear regression analysis. Significance was considered at the $p<0.05$ level.

\section{RESULTS}

We studied seven fetal lambs at a mean gestational age of 134 \pm 2 days (range 130-137 days), and at 2-3 days postoperatively. They weighed $3350 \pm 796 \mathrm{~g}$ and at the time of study had mean arterial $\mathrm{pH} 7.36 \pm 0.08, \mathrm{pO}_{2} 16.7 \pm 2.8, \mathrm{pCO}_{2} 54.3 \pm 5.6$, oxygen saturation $40.2 \pm 11.1 \%$, hemoglobin concentration $11.9 \pm 1.9$ $\mathrm{g} / \mathrm{dl}$, lactate concentration $25.5 \pm 17 \mathrm{mg} / \mathrm{dl}$, and glucose concentration $11.9 \pm 2.6 \mathrm{mg} / \mathrm{dl}$ (Table 1). One fetus (no. 7) was acidotic with high lactate concentration at the beginning of the study and remained acidotic but stable throughout the study. No abnormalities were detected at autopsy.

Arterial blood gas changes during ventilation $\left(3 \% \mathrm{O}_{2}, 5 \% \mathrm{CO}_{2}\right.$, $\left.92 \% \mathrm{~N}_{2}\right)$ and during ventilation/oxygenation $\left(95 \% \mathrm{O}_{2}, 5 \% \mathrm{CO}_{2}\right)$ are shown in Table 1 . There were no significant changes in fetal blood gases with ventilation alone. Ventilation with $95 \% \mathrm{O}_{2}$, however, caused a significant increase from control values in arterial $\mathrm{pO}_{2}(16.7 \pm 2.8$ to $156.3 \pm 96.1$ torr, $p<0.005)$ and in oxygen saturation $(40.2 \pm 11.1$ to $96.3 \pm 7.5 \%, p<0.005)$. The increase in $\mathrm{pO}_{2}$ varied considerably; fetus 5 showed an increase from 15.1 to 33.5 torr whereas fetus 4 increased $\mathrm{pO}_{2}$ dramatically 
Table 1. Fetal gestational age and wt, and arterial blood gases and oxygen saturation obtained from the descending aorta of seven fetal lambs during the control period, during ventilation, and during ventilation/oxygenation*

\begin{tabular}{|c|c|c|c|c|c|c|c|c|c|c|c|c|c|c|}
\hline \multirow[b]{2}{*}{$\begin{array}{c}\text { Sheep } \\
\text { no. }\end{array}$} & \multirow[b]{2}{*}{$\begin{array}{l}\text { Gestational } \\
\text { age (days) }\end{array}$} & \multirow[b]{2}{*}{$\begin{array}{l}\text { Wt } \\
(\mathrm{g})\end{array}$} & \multicolumn{4}{|c|}{ Control } & \multicolumn{4}{|c|}{ Ventilation } & \multicolumn{4}{|c|}{ Ventilation/oxygenation } \\
\hline & & & $\mathrm{pH}$ & $\mathrm{pCO}_{2}$ & $\mathrm{pO}_{2}$ & $\begin{array}{c}\% \\
\text { Saturation }\end{array}$ & $\mathrm{pH}$ & $\mathrm{pCO}_{2}$ & $\mathrm{pO}_{2}$ & $\begin{array}{c}\% \\
\text { Saturation }\end{array}$ & $\mathrm{pH}$ & $\mathrm{pCO}_{2}$ & $\mathrm{pO}_{2}$ & $\begin{array}{c}\% \\
\text { Saturation }\end{array}$ \\
\hline 1 & 135 & 2415 & 7.39 & 53.4 & 18.2 & 49.2 & 7.38 & 49.8 & 20.3 & 56.6 & 7.33 & 51.7 & 283 & 102.3 \\
\hline 2 & 135 & 3290 & 7.39 & 44.9 & 22.4 & 59.9 & 7.33 & 44.4 & 23.4 & 57.0 & 7.29 & 50.8 & 151.7 & 100.4 \\
\hline 3 & 133 & 3005 & 7.39 & 55.4 & 15.4 & 43.1 & 7.40 & 50.7 & 15.0 & 37.2 & 7.46 & 40.0 & 181 & 96.1 \\
\hline 4 & 133 & 2845 & 7.38 & 53.7 & 14.8 & 30.5 & 7.37 & 53.2 & 17.9 & 34.5 & 7.37 & 50.8 & 271.2 & 98.1 \\
\hline 5 & 135 & 3265 & 7.38 & 58.9 & 15.1 & 32.8 & 7.33 & 60.5 & 15.7 & 31.0 & 7.28 & 65.7 & 33.5 & 80.0 \\
\hline 6 & 130 & 3730 & 7.41 & 51.5 & 15.0 & 34.0 & 7.39 & 51.0 & 17.0 & 47.0 & 7.30 & 60.0 & 107 & 100.0 \\
\hline 7 & 137 & 4900 & 7.18 & 62.6 & 16.3 & 31.8 & 7.13 & 56.6 & 24.4 & 53.7 & 7.19 & 60.0 & 66.7 & 97.1 \\
\hline $\begin{array}{l}\text { Mean } \\
( \pm \text { SD) }\end{array}$ & $\begin{array}{l}134 \\
(2.2)\end{array}$ & $\begin{array}{l}3350 \\
(796)\end{array}$ & $\begin{array}{c}7.36 \\
(0.08)\end{array}$ & $\begin{array}{l}54.3 \\
(5.6) \\
\end{array}$ & $\begin{array}{l}16.7 \\
(2.8)\end{array}$ & $\begin{array}{c}40.2 \\
(11.1)\end{array}$ & $\begin{array}{c}7.33 \\
(0.09) \\
\end{array}$ & $\begin{array}{l}52.3 \\
(5.16)\end{array}$ & $\begin{array}{l}19.1 \\
(3.7)\end{array}$ & $\begin{array}{c}45.3 \\
(11.0)\end{array}$ & $\begin{array}{c}7.32 \\
(0.08)\end{array}$ & $\begin{array}{l}54.1 \\
(8.5)\end{array}$ & $\begin{array}{l}156.3 \\
(96.1)\end{array}$ & $\begin{array}{l}96.3 \\
(7.5)\end{array}$ \\
\hline
\end{tabular}

* Blood samples were drawn from the fetal descending aorta during the control period. The fetal tracheal catheter was then disconnected from the amniotic catheter and allowed to drain lung fluid. The fetal lungs were manually ventilated with a gas mixture of $3 \% \mathrm{O}_{2}, 5 \% \mathrm{CO}_{2}$, and $92 \% \mathrm{~N}_{2}$ at a rate of 40-50 breaths $/ \mathrm{min}$. Ventilation was continued for $15 \mathrm{~min}$ and blood samples were then drawn as in the control period. The gas mixture was then changed to $5 \% \mathrm{CO}_{2}, 95 \% \mathrm{O}_{2}$, and ventilation was continued for 15-55 min (mean $32 \mathrm{~min}$ ). Blood samples were drawn when fetal arterial $\mathrm{pO}_{2}$ had increased significantly from control values.

Table 2. Glucose (Glu) and lactate (Lact) concentrations $(\mathrm{mg} / \mathrm{dl})$ and $\mathrm{HV}$-UV ${ }^{14} \mathrm{C}$-glucose and glucose concentration difference (HV$U V)$ during the control period, during ventilation, and during ventilation/oxygenation in seven fetal lambs

\begin{tabular}{|c|c|c|c|c|c|c|c|c|c|c|c|c|}
\hline \multirow[b]{2}{*}{$\begin{array}{c}\text { Sheep } \\
\text { no. }\end{array}$} & \multicolumn{4}{|c|}{ Control } & \multicolumn{4}{|c|}{ Ventilation } & \multicolumn{4}{|c|}{ Ventilation/oxygenation } \\
\hline & $\begin{array}{c}(\mathrm{Glu}) \\
(\mathrm{mg} / \mathrm{dl})\end{array}$ & $\begin{array}{c}\text { (Lact) } \\
(\mathrm{mg} / \mathrm{dl})\end{array}$ & $\begin{array}{c}\text { (C Glu) } \\
\text { HV-UV } \\
(\mathrm{dpm} / \mathrm{ml})\end{array}$ & $\begin{array}{c}\text { (Glu) } \\
\text { HV-UV } \\
(\mathrm{mg} / \mathrm{dl})\end{array}$ & $\begin{array}{c}(\mathrm{Glu}) \\
(\mathrm{mg} / \mathrm{dl})\end{array}$ & $\begin{array}{c}(\mathrm{Lact}) \\
(\mathrm{mg} / \mathrm{dl})\end{array}$ & $\begin{array}{c}\text { (C Glu) } \\
\text { HV-UV } \\
(\mathrm{dpm} / \mathrm{ml})\end{array}$ & $\begin{array}{c}\text { (Glu) } \\
\text { HV-UV } \\
(\mathrm{mg} / \mathrm{dl})\end{array}$ & $\begin{array}{c}(\mathrm{Glu}) \\
(\mathrm{mg} / \mathrm{dl})\end{array}$ & $\begin{array}{c}\text { (Lact) } \\
\text { (mg/dl) }\end{array}$ & $\begin{array}{c}\text { (C Glu) } \\
\text { HV-UV } \\
(\mathrm{dpm} / \mathrm{ml})\end{array}$ & $\begin{array}{c}\text { (Glu) } \\
\text { HV-UV } \\
\text { (mg/dl) }\end{array}$ \\
\hline 1 & 8.2 & 11.8 & 194.5 & -0.2 & 14.1 & 24.5 & 298 & 18.8 & 12.7 & 23.6 & 368 & 3.8 \\
\hline 2 & 10.9 & 12.9 & -51.5 & 0.5 & 23.9 & 25.1 & 237 & 7.2 & 25.2 & 28.6 & 191 & 3.3 \\
\hline 3 & 12.6 & 23.7 & -31 & 0.3 & 16.3 & 26.8 & -25 & 1.7 & 20.7 & 35.3 & -128 & 2.4 \\
\hline 4 & 14.0 & 21.5 & 65 & 0 & 15.1 & 21.5 & -18 & -0.2 & 20.6 & 16.5 & -133 & 1.4 \\
\hline 5 & 14.0 & 15.0 & -98 & -0.1 & 19.9 & 20.3 & 426 & 9.4 & 17.7 & 19.9 & -68 & 0.4 \\
\hline 6 & 14.7 & 33.0 & 50 & 0.9 & 22.8 & 31.0 & 139 & 7.6 & 27.5 & 33.6 & 170 & 4.1 \\
\hline 7 & 9.0 & 60.1 & 314 & 0.8 & 10.9 & 77.6 & 189 & 3.5 & 9.3 & 81.1 & 576 & 0.3 \\
\hline $\begin{array}{l}\text { Mean } \\
( \pm \mathrm{SD})\end{array}$ & $\begin{array}{l}11.9 \\
(2.6)\end{array}$ & $\begin{array}{l}25.5 \\
(17)\end{array}$ & $\begin{array}{c}63.3 \\
(146)\end{array}$ & $\begin{array}{c}0.3 \\
(0.4)\end{array}$ & $\begin{array}{l}17.6 \\
(4.8)\end{array}$ & $\begin{array}{c}32.4 \\
(20.2)\end{array}$ & $\begin{array}{c}178 \\
(163)\end{array}$ & $\begin{array}{c}6.9 \\
(6.3) \\
\end{array}$ & $\begin{array}{l}19.1 \\
(6.5) \\
\end{array}$ & $\begin{array}{c}34.1 \\
(21.8)\end{array}$ & $\begin{array}{c}139 \\
(269)\end{array}$ & $\begin{array}{c}2.2 \\
(1.6) \\
\end{array}$ \\
\hline
\end{tabular}

from 14.7 to 271.2 torr. All fetuses had increases of arterial oxygen saturation to greater than $80 \%$ (Table 2 ).

The HV-UV difference in ${ }^{14} \mathrm{C}$-glucose concentration was not significantly different from control during either the ventilation period or the ventilation/oxygenation period (Table 2). In addition, there was no difference in the $\mathrm{HV}-\mathrm{UV}{ }^{14} \mathrm{C}$-glucose concentration when the ventilation/oxygenation period was compared with the ventilation period. During all three study periods, the ${ }^{14} \mathrm{C}$-glucose concentration in all blood samples was small $(200$ $800 \mathrm{dpm} / \mathrm{ml}$ ) when compared with the total ${ }^{14} \mathrm{C}$-radioactivity $(12,000-33,000 \mathrm{dpm} / \mathrm{ml})$. We have previously shown that, given these concentrations, gluconeogenesis is negligible (2).

Although there was no evidence of hepatic gluconeogenesis, arterial glucose concentration, as well as the hepatic arteriovenous glucose difference (HV-UV glucose) increased significantly from control during both ventilation and ventilation/oxygenation (Table 2). However, there was no difference in glucose concentration when the ventilation/oxygenation period was compared to the ventilation period, nor was there any correlation between glucose concentration and $\mathrm{pO}_{2}$ during any of the study periods.

Lactate concentration also increased significantly from control during both the ventilation and ventilation/oxygenation periods. There was, however, no difference in lactate concentration when the ventilation period was compared to the ventilation/oxygenation period.

\section{DISCUSSION}

Our results show that neither physical expansion of the lungs nor an increase in arterial oxygen saturation stimulates hepatic gluconeogenesis in fetal lambs near term.

Warnes et al. (4) injected ${ }^{14} \mathrm{C}$-lactate intravenously into fetal lambs and noted no ${ }^{14} \mathrm{C}$-glucose production until $2 \mathrm{~min}$ after delivery by cesarean section. ${ }^{14} \mathrm{C}$-glucose production was delayed in prematurely delivered lambs until breathing was established and their blood was fully oxygenated. Previous studies in young rats (15) had noted that hepatic gluconeogenesis decreased when the animals were made moderately hypoxic. Based on these studies, Warnes et al. (4) speculated that oxygenation could stimulate hepatic gluconeogenesis in newborn animals by altering the redox potential of the hepatocyte. Cuezva and Medina (16) studied the effects of changes in oxygen supply on utilization of metabolic fuels in newborn rats and found that increasing the oxygen supply to the tissues enhanced hepatic utilization of lactate, alanine, and glucose while the rate of glycogenolysis remained the same. Kashiwagura et al. (17) studied the dependency of gluconeogenesis on oxygen concentration in isolated rat hepatocytes and found that as the oxygen concentration decreased to less than $20 \mu \mathrm{M}$, gluconeogenic activity was reduced. Based on these three studies, if gluconeogenic activity were to be stimulated by increased oxygen availability at birth, one would expect hepatic oxygenation to increase at birth. However, the 
newborn liver actually has decreased blood supply and receives less oxygen than the fetal liver since the well-oxygenated umbilical venous supply is abruptly discontinued at birth (18). It is not surprising, then, that our results show that oxygenation alone does not stimulate hepatic gluconeogenesis in fetal lambs. However, many metabolic and physiologic changes occur during the birth process and it is possible that oxygenation may serve as a necessary cofactor in triggering the gluconeogenic pathway.

The isotope methodology we used to measure gluconeogenesis relies on a steady state of labeled lactate. Chiasson et al. (19) used similar methodology to measure glucose production from alanine in adult humans. They observed that it is difficult to obtain an absolute steady state and the variability of labeled alanine concentration over 10-100 min was $6 \%$. In our studies, variability from $15-180 \mathrm{~min}$ after beginning the infusion was $18.2 \%$. Furthermore, it is likely that some of the labeled carbon from lactate could cross into the tricarboxylic acid cycle, and some labeled carbon that has passed into this cycle may then transfer back into the gluconeogenic pathway. There may therefore be some error in the calculation of gluconeogenesis from lactate; the amount of glucose formed is probably underestimated to some extent because of loss of labeled carbon cycling in the tricarboxylic acid cycle.

Arterial glucose concentrations and the hepatic arteriovenous glucose difference (HV-UV glucose) did increase significantly with ventilation and remained elevated when oxygenation was added. Because there was no evidence that this glucose production resulted from hepatic gluconeogenesis, it must have been caused by glygogenolysis. Bristow et al. (1) reported hepatic glucose production during acute hypoxia in fetal lambs, but our fetuses were either normoxic or hyperoxic during the studies. It is possible that hormonal changes occurring during either hypoxemia or ventilation stimulate hepatic glycogenolysis. We did not measure hormonal concentrations during these studies, but at birth, concentrations of catecholamines, glucagon, and cortisol increase dramatically, and ventilation could be one of the stimuli. Another stimulus of hepatic glycogenolysis could be a change in hepatic blood flow. During ventilation and oxygenation it is likely that hepatic blood flow decreases because umbilical blood flow may be reduced. Although it is only speculative, decreased hepatic blood flow, which is known to occur at birth as well as during fetal hypoxemia, may stimulate hepatic glycogenolysis.

Alternative mechanisms that may stimulate hepatic gluconeogenesis at birth include hormonal surges, surges in catecholamines, increased fatty acid oxidation, and postnatal hypogly- cemia. These mechanisms all require further investigation and may be studied in utero with this model.

\section{REFERENCES}

1. Bristow J, Rudolph AM, Itskovitz J, Barnes R 1983 Hepatic oxygen and glucose metabolism in the fetal lamb. Response to hypoxia. $\mathrm{J}$ Clin Invest 71:1047-1061

2. Gleason C, Rudolph AM 1985 Gluconeogenesis by the fetal sheep liver in vivo. J Dev Physiol 7:185-194

3. Stevenson RE, Morris FH Jr, Adcock EW III, Howell ER 1976 Development of gluconeogenic enzymes in fetal sheep liver and kidney.Dev Biol 52:167172

4. Warnes DM, Seamark RF, Ballard FJ 1977 The appearance of gluconeogenesis at birth in sheep-activation of the pathway associated with blood oxygenation. Biohem J 162:627-634

5. Cake MH, Yeung D, Oliver IT 1971 The control of postnatal hypoglycemia. Biol Neonate 18:183-192

6. Clark MG, Filsell OH, Jarrett IG 1976 Gluconeogenesis in isolated intact lamb liver cells. Effects of glucagon and butyrate. Biochem J 156:671-680

7. Adam PAJ, Glazer G, Rogoff F 1975 Glucose production in the newborn dog. I. Effects of glucagon in vivo. Pediatr Res 9:816-820

8. Grajwer LA, Sperling MA, Sack J, Fisher DA 1977 Possible mechanisms and significance of the neonatal surge in glucagon secretion: studies in newborn lambs. Pediatr Res 11:833-836

9. Shelley HJ, Bassett JM 1975 Control of carbohydrate metabolism in the fetus and newborn. Br Med Bull 31:37-43

10. Kriz BM, Jones AL, Jorgensen EC 1978 Effects of a thyroid hormone analog on fetal rat hepatocyte ultrastructure and microsomal function. Endocrinology 102:712-722

11. Girard J 1981 Glucose homeostasis in the prenatal period: the critical role of pancreatic hormones and exogenous substrates in the rat. In: Elliott $\mathrm{K}$, Whelan J (eds) The Fetus and Independent Life. CIBA Foundation Symposium 86, Pitman, Ltd., London, pp 234-250

12. Yeung D, Oliver IT 1968 Factors affecting the premature induction of phosphopyruvate carboxylase in neonatal rat liver. Biochem J 108:325-331

13. Bristow J, Rudolph J, Rudolph AM, Itskovitz J 1981 A preparation for studying liver blood flow, oxygen consumption and metabolism in the fetal lamb in utero. J Dev Physiol 3:255-266

14. Hay WW Jr, Sparks JW, Quissell BJ, Battaglia FC, Meschia G 1981 Simultaneous measurements of umbilical uptake, fetal utilization rate and fetal turnover rate of glucose. Am J Physiol 240:E662-E668

15. Ballard FJ 1971 Regulation of gluconeogenesis during exposure of young rats to hypoxic conditions. Biochem J 121:169-178

16. Cuezva JM, Medina JM 1981 Prematurity in the rat. III. Effect of oxygen supply. Biol Neonate 39:70-77

17. Kashiwagura T, Wilson DF, Erecinska M 1984 Oxygen dependence of cellular metabolism: the effect of $\mathrm{O}_{2}$ tension on gluconeogenesis and urea synthesis in isolated rat hepatocytes. J Cell Physiol 120:13-18

18. Gleason CA, Roman C, Rudolph AM 1985 Hepatic oxygen consumption, lactate uptake, and glucose production in neonatal lambs. Pediatr Res 19:1235-1239

19. Chiasson JL, Liljenquist JE, Sinclair-Smith BC, Lacy WW 1975 Gluconeogenesis from alanine in normal postabsorptive man. Intrahepatic stimulatory effect of glucagon. Diabetes 24:574-584 